\title{
Preseptal Transconjunctival Approach: A Retrospective Review
}

\author{
Shaifulizan Ab Rahman ${ }^{1}$, Mohd SF Mohamad ${ }^{1}$, Sanjida Haque ${ }^{2}$, Mohammad K Alam³
}

\begin{abstract}
Aim: The aim of this study was to determine types of facial fractures that use the preseptal transconjunctival approach and to evaluate the lower eyelid condition.

Materials and methods: Ninety-one patients who underwent open reduction internal fixation of facial fractures using preseptal transconjunctival approach from 2005-2013 were included and analyzed from clinical records. We evaluate the incidence of postoperative complication such as visible scar at rest, entropion, ectropion, scleral show, trichiasis, conjunctival granuloma, lower eyelid laceration, corneal lesion, and lacrimal drainage lesion. The types of facial fractures that frequently use this approach were also analyzed.

Results: Four out of ninety-one patients were excluded because of insufficient data. Zygomatic complex fracture occurring in isolation or combination with other fracture was the commonest fracture type encountered (93.5\%). Two complications (entropion and trichiasis) occurred in one out of eighty-seven patients. The complication rate in this study was very low at $1.1 \%$.

Conclusion: A preseptal transconjuctival approach is a versatile approach that can be used in all mid-face fracture situations providing an alternative to the invasive transcutaneous approach. It provides minimal complications with superior esthetic result.

Clinical significance: The management of facial fractures that involve orbital rim or floor often poses a challenge to the surgeon because surgeons aim for complete repair of the orbital anatomy with least complication and superior esthetic result. Two surgical incisions existed in the process of reaching orbital bony component which is the transcutaneous and transconjunctival approach. It will help clinicians to know which approach provides minimal complication.
\end{abstract}

Keywords: Complication, Facial fractures, Preseptal transconjunctival approach.

World Journal of Dentistry, (2019): 10.5005/jp-journals-10015-1612

\section{INTRODUCTION}

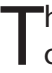
he maxillofacial geography is synonymous as the primary area of esthetic concern. Therefore, the surgeon must take into consideration the exposure needed for operative access versus aesthetic concern of the patient before deciding on an appropriate surgical approach. ${ }^{1-3}$ The management of facial fractures that involve orbital rim or floor often poses a challenge to the surgeon. With the research and development over the years, current improvement of the orbital mini plate plating systems proves to be beneficial for surgeons around the world in providing the best choice of treatment for patients. Surgeons aim for complete repair of the orbital anatomy with least complication and superior esthetic result. ${ }^{1}$

Two surgical incisions existed in the process of reaching the orbital bony component which is the transcutaneous and transconjunctival approach. Each of these approaches offers advantages and disadvantages depending on the condition and severity of the injuries that the patient has. ${ }^{1}$ The transcutaneous approach, being a more popular approach used by maxillofacial surgeons in Malaysia, produces complications of eyelid deformity such as ectropion and visible cutaneous surgical scars. ${ }^{1}$ The transconjunctival approach which was first used and described by Bourguet ${ }^{2}$ and later popularized by Tessier ${ }^{3}$ provide excellent fracture site exposure with minimal long term postoperative surgical site complication with an emphasis on ectropion and entropion.

However, some authors suggested that the transconjunctival approach takes longer learning time compared to a transcutaneous approach and more time consuming intraoperatively. ${ }^{4,5}$ Furthermore, some surgeons often indicate that the procedure of transconjunctival approach restricts access to the orbital bony support systems when compared to the transcutaneous approach. ${ }^{6}$

A Malaysian-based review of the preseptal transconjunctival approach for internal fixation of orbital floor fractures has never
${ }^{1}$ Department of Oral Surgery and Maxillofacial Surgery, School of Dental Science, Universiti Sains Malaysia, Kubang Kerian, Kota Bharu, Kelantan, Malaysia

${ }^{2}$ Department of Orthodontics, School of Dental Sciences, Universiti Sains Malaysia, Kubang Kerian, Kota Bharu, Kelantan, Malaysia

${ }^{3}$ Department of Orthodontics, College of Dentistry, Jouf University, Sakaka, Kingdom of Saudi Arabia

Corresponding Author: Shaifulizan Ab Rahman, Department of Oral Surgery and Maxillofacial Surgery, School of Dental Science, Universiti Sains Malaysia, Kubang Kerian, Kota Bharu, Kelantan, Malaysia, Phone: +609-7675821, e-mail: shaiful@usm.my

How to cite this article: Rahman SAB, Mohamad MSF, Haque S, Alam MK. Preseptal Transconjunctival Approach. World J Dent 2019;10(2): 98-102.

Source of support: Nil

Conflict of interest: None

been published before. Such a review in the nation's context is very important to popularize this surgical approach among oral and maxillofacial surgeons in Malaysia. With the clinical data received, it could be a guide for oral and maxillofacial surgeons in selecting the best surgical approach in managing open reduction and internal fixation of orbital fractures. Based on these, the aim of our study was to evaluate the lower eyelid condition after preseptal transconjunctival approach from 2005 to 2013 and also to determine types of facial fractures that uses preseptal transconjunctival approach.

\section{Materials AND METHOdS}

This study was approved by the Ethical Committee of the Hospital Universiti Sains Malaysia (HUSM).

All patients who had received treatment for facial fracture via preseptal transconjuctival approach in HUSM from 2005 to

() The Author(s). 2019Open Access This article is distributed under the terms of the Creative Commons Attribution 4.0 International License (http://creativecommons. org/licenses/by/4.0/), which permits unrestricted use, distribution, and non-commercial reproduction in any medium, provided you give appropriate credit to the original author(s) and the source, provide a link to the Creative Commons license, and indicate if changes were made. The Creative Commons Public Domain Dedication waiver (http://creativecommons.org/publicdomain/zero/1.0/) applies to the data made available in this article, unless otherwise stated. 
2013 were included in this retrospective study. Medical records of all patients were studied. The respective medical records were obtained from the Medical Record Unit, HUSM. Information taken from medical records was recorded in data retrieval form. Figure 1 shows the data retrieval form.

The inclusion criteria of this study were:

- Patients who underwent preseptal transconjuctival approach for orbital trauma.

- Patients with documented follow-up of at least 3 months postsurgery.

Patient who underwent preseptal transconjunctival approach for craniofacial resection and patient whose file was not available were excluded from this study.

Ninety-one clinical records of patients who have undergone preseptal transconjunctival approach for open fixation of various fracture types were traced from the medical record unit, HUSM. The patients were gathered from the operating theatre census as well as surgeons' compilation from the year 2005 till 2013 accounting to 9 years. Out of these, four patients were excluded. Three of the medical records were untraceable and one was excluded due to insufficient data. Finally, 87 patient's clinical records remained for data analysis.

\section{Results}

\section{Demographic Data}

Among 87 patients, 76 were male patients and 11, female patients. Mean age of the study population was 22 years old with the majority of the patients fall into the $16-25$ years old age group. The racial distribution of our study population was composed of predominant Malay patients (96.5\%). There were four Chinese patients (3.5\%). No Indian patients other races or Thai immigrants within the study (Table 1).

\section{Vehicle Pattern}

Type of vehicle implicated in respective patients' road traffic accident was obtained from the patients' record. It was observed that 77 patients $(88.5 \%)$ were riding a motorcycle. Out of the 77 patients, 72 patients (93.5\%) were driving during the collision, and only 5 patients $(6.5 \%)$ were pillion riders (Fig. $2 \mathrm{~A})$. The remaining 10 patients (11.5\%) were driving a car. Out of these 10 patients, 9 (90.0\%) was assuming the driver's role during the collision and 1 (10.0\%) was beside the driver (Fig. 2B).

\section{Fracture Pattern}

Seventy-two patients (93.5\%) suffered from zygomatic complex fractures occurring in isolation or combination with other types of facial fracture. The isolated zygomatic complex fracture was present in 45 patients (51.7\%). Zygomatic fracture in combination with lefort II occurred in 13 patients (14.9\%) whilst in combination with unilateral lefort II occurred in 4 patients (4.6\%). Lefort II occurred in 18 patients $(20.7 \%)$, orbital floor fracture in 5 patients $(5.7 \%)$ and isolated orbital rim fracture in 2 patients (2.3\%).

\section{Complications}

No intraoperative complications were recorded in our series. All fractures were adequately exposed using the transconjunctival approach, and no patients had to undergo a second procedure due to inadequate fixation. Two complications (entropion and trichiasis) occurred in one patient out of a total of 87 patients. Table 2 shows the transconjunctival approach in various midfacial fractures.

\section{Statistical Analysis}

All the analysis was done into statistical package for the social sciences version 20.0 (SPSS Inc., Chicago, IL, USA). Descriptive analysis was performed. Percentage recorded is in nearest one decimal point. Mean was used as a central tendency for demographic data.

\section{Discussion}

In this study, the majority of the patients were from the young adult age group. Mean age was 22 years old with $65.5 \%$ of the patients fall into the 16-25 years old age group. Our data characteristic supports findings by Nordin et al. ${ }^{7}$ in which sociodemographically, young Malay adult in the age group of 16-25 (65.5\%) was the largest group involved in facial trauma. Their study recruited patients from two major tertiary hospitals in Malaysia which are Hospital Universiti Sains Malaysia and Hospital Universiti Kebangsaan Malaysia.

There were a total of 76 male patients in this study compared to a minute 11 female patients. The high male predilection gives rise to nearly 7:1 male:female predominance. This result was reproducible in similar studies conducted in HUSM where male preponderance was $77 \%$ compared to $23 \%$ female. $^{7}$ There are many reasons for this scenario. The motorcycle is a common mode of transport among Malaysians. In this study, the majority (88.5\%) of the patients involved were a motorcyclist. This finding was consistent with another study on road traffic accidents in Malaysia. ${ }^{8}$ Additionally, an international study published by the World Health Organization reported that $59 \%$ of road traffic accident fatalities in Malaysia involved motorcyclist.

In our study population, the most common type of fractures was the zygomatic complex fractures (71.2\%). Similar findings also reported by Nordin. ${ }^{7}$ However, they reported a lower incidence of $15.6 \%$ compared to our series. We believe that the high incidence of zygomatic complex fractures is related to poor head safety practices among motorcyclists. In Malaysia, it is compulsory for motorcyclists to wear a helmet when riding the motorcycle. However, there is no strict regulation regarding the type of helmet to be used. Another potential reason for the higher incidences of zygomatic complex fractures is an insecure helmet. Insecure helmets are a result of insecure chin straps or not wearing a correctly sized helmet. The insecure helmet will easily get displaced during a high impact collision. Only secured helmets which remain attached to the cranium during a collision will provide some protection to the maxillofacial area. ${ }^{9}$ Thus, to decrease the incidence of midface trauma, we believe more attention should be given by enforcement agencies on, existing regulations regarding the type of helmet and helmet safety protocols.

In this study, the transconjunctival approach for internal fixation of midfacial fracture has a very low complication rate at $1.1 \%$. This figure was consistent with recent studies. Baumann et al. ${ }^{10}$ in his series of 99 patients reported a similar complication rate at $2 \%$. They reported temporary entropion and laceration of tarsal plate. Giorgio et al. ${ }^{11}$ in his series of 56 cases reported a higher complication rate of $7 \%$. From their review, they reported temporary partial entropion and trichiasis which resolved completely in 2 months with simple palpebral massages.

From 87 patients who underwent preseptal transconjunctival approach only one patient developed complication. The complications encountered were entropion and trichiasis. The patient had multiple fractures of facials bone involving the zygoma and Lefort II fractures; hence we believed due to the severity of the trauma the complication was exaggerated with over manipulation 
Date Retrieval from

Patient No.

Notes:

Demographic Data

Name:

Registration No. Gender M/F Race: M/ C/ I/ O:

Age:

Date of Accident: Date of Admission:

Mechanism of injury: Date of Discharge:

\begin{tabular}{|l|l|l|l|l|}
\hline Motorcyclist & Driver & Helmet & \\
\hline & & Piilon Rider & No Helmet & \\
\hline Car & Driver & Seatbelt & \\
\hline Lorry & Co-D river & No seatbelt & \\
\hline Van & Backseat $p$ & & & \\
\hline
\end{tabular}

Injuries sustained:

Operative Data

Date of Operation:

Time start: Time end:

Operative Procedure

\begin{tabular}{|l|l|}
\hline Type of fracture & \\
\hline Le fort II + zygoma & \\
\hline Le fort II & \\
\hline Le fort II (uni) + zygoma & \\
\hline Zygoma & \\
\hline Orbital floor & \\
\hline Orbital rim (iso) & \\
\hline
\end{tabular}

Postoperative Data

\begin{tabular}{|l|l|l|}
\hline Parameter & Yes & No \\
\hline Visible surgical scar at rest & & \\
\hline Presence of ectropion & & \\
\hline Presence of entropion & & \\
\hline Lower eyelid laceration & & \\
\hline Excess tearing & & \\
\hline Presence of comeal lesion & & \\
\hline Presence of granuloma & & \\
\hline Scleral show & & \\
\hline Trichiasis & & \\
\hline
\end{tabular}

Fig. 1: Data retrieval form 
Table 1: Demographic data of study population

\begin{tabular}{lll}
\hline & & $\begin{array}{l}\text { Total number of patients, } \\
n(\%) N=87\end{array}$ \\
\hline Age group & & \\
$<16$ years & $16-25$ years & $57(65.5 \%)$ \\
& $26-40$ years & \\
\hline 40 years & $14(15.9 \%)$ & \\
& $4(4.8 \%)$ & $76(87.4 \%)$ \\
\hline Gender & Male & $11(12.6 \%)$ \\
& Female & $84(96.5 \%)$ \\
& Malay & $3(3.5 \%)$ \\
& Chinese & $0(0 \%)$ \\
& Indian & $0(0 \%)$ \\
\hline
\end{tabular}

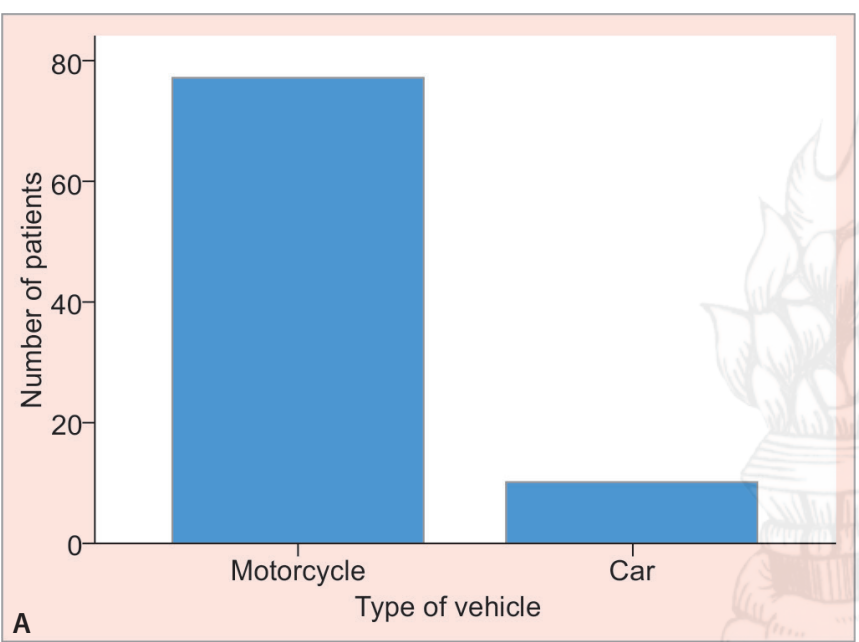

and extraction of the soft tissue. To avoid complications, respect of the soft tissue and anatomy of the planes during the intraoperative procedures must be implemented by the assistant and surgeons. ${ }^{11}$ One author even suggested that conditions affecting nasoethmoidal-orbital or fractures involving the floor of the orbit, the transconjunctival approach should be avoided. ${ }^{12}$ On the contrary, we think this approach can be extended by lateral canthotomy or combined with another approach such as the coronal and vestibular approach to avoid violating the facial area.

In our study, the transconjunctival approach has excellent aesthetic outcomes. No patients had visible surgical scars at rest, and there were no cases of lower eyelid laceration. This is a pertinent advantage of this surgical technique. When compared with the transconjunctival approach, there is some evidence to suggest that the subciliary approach causes more cutaneous scarring, hence poorer cosmesis. ${ }^{13-15}$ Similar point was highlighted by Giorgio et al. ${ }^{11}$ in his review of 56 cases where he concluded the transconjunctival approach to have better aesthetic result than the

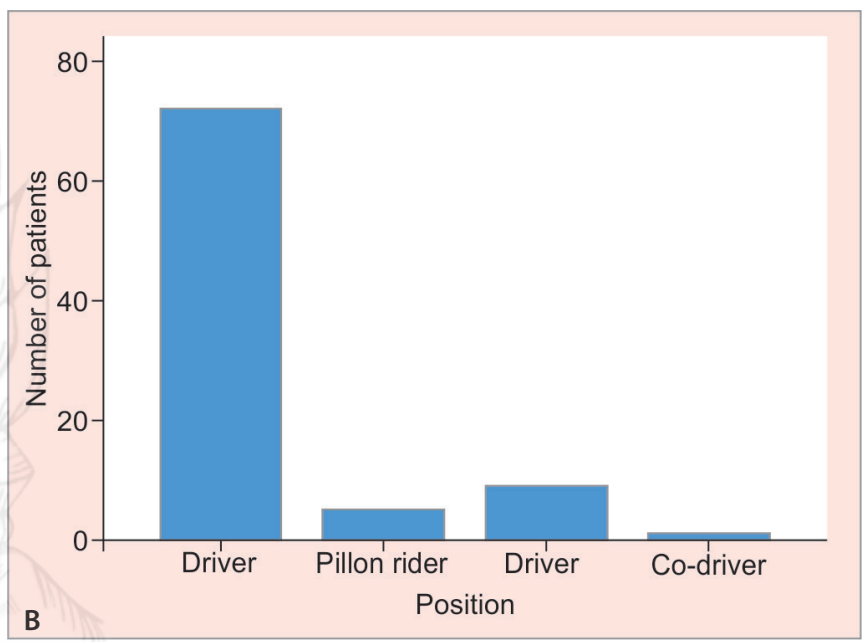

Figs 2A and B:. (A) Type of vehicle involved in a road traffic accident; (B) Patient position during a collision

Table 2: Transconjunctival approach in various midfacial fractures

\begin{tabular}{clll}
\hline Patient & Age & Diagnosis & Complication \\
\hline 1 & 30 & Le Fort 2 + Zygoma & No complication \\
2 & 27 & Zygoma & No complication \\
3 & 25 & Unilat Le Fort 2 + Zygoma & No complication \\
4 & 23 & Zygoma & No complication \\
5 & 18 & Zygoma & No complication \\
6 & 17 & Zygoma & No complication \\
7 & 18 & Le Fort 2 & No complication \\
8 & 16 & Zygoma & No complication \\
9 & 21 & Orbital floor & No complication \\
10 & 25 & Zygoma & No complication \\
11 & 18 & Zygoma & No complication \\
12 & 26 & Le Fort 2 + Zygoma & No complication \\
13 & 26 & Zygoma & No complication \\
14 & 21 & Zygoma & No complication \\
15 & 26 & Zygoma & No complication \\
16 & 18 & Zygoma & No complication \\
17 & 22 & Zygoma & No complication \\
18 & 20 & Zygoma & No complication \\
19 & 53 & Zygoma & No complication \\
20 & 56 & Le Fort 2 & No complication \\
21 & 23 & Le Fort 2 & No complication \\
\hline
\end{tabular}

(Contd...)

\begin{tabular}{llll}
\hline Patient & Age & Diagnosis & Complication \\
\hline 22 & 17 & Zygoma & No complication \\
23 & 18 & Zygoma & No complication \\
24 & 25 & Le Fort 2 & No complication \\
25 & 18 & Zygoma & No complication \\
26 & 20 & Zygoma & No complication \\
27 & 18 & Zygoma & No complication \\
28 & 18 & Le Fort 2 & No complication \\
29 & 17 & Zygoma & No complication \\
30 & 13 & Zygoma & No complication \\
31 & 10 & Zygoma & No complication \\
32 & 28 & Zygoma & No complication \\
33 & 14 & Zygoma & No complication \\
34 & 18 & Zygoma & No complication \\
35 & 13 & Orbital floor & No complication \\
36 & 18 & Zygoma & No complication \\
37 & 34 & Zygoma & No complication \\
38 & 22 & Le Fort 2 & No complication \\
39 & 23 & Le Fort 2 & No complication \\
40 & 23 & Le Fort 2 & No complication \\
41 & 24 & Le Fort 2 & No complication \\
42 & 22 & Zygoma & No complication \\
\hline & & & (Contd...)
\end{tabular}


Contd...

\begin{tabular}{|c|c|c|c|}
\hline Patient & Age & Diagnosis & Complication \\
\hline 43 & 15 & Zygoma & No complication \\
\hline 44 & 25 & Le Fort 2 + zygoma & No complication \\
\hline 45 & 20 & Zygoma & No complication \\
\hline 46 & 42 & Unilat Le Fort 2 + zygoma & No complication \\
\hline 47 & 15 & Isolated orbital rim & No complication \\
\hline 48 & 36 & Zygoma & No complication \\
\hline 49 & 20 & Zygoma & No complication \\
\hline 50 & 23 & Le Fort 2 & No complication \\
\hline 51 & 30 & Le Fort 2 & No complication \\
\hline 52 & 20 & Zygoma & No complication \\
\hline 53 & 15 & Zygoma & No complication \\
\hline 54 & 19 & Le Fort 2 & No complication \\
\hline 55 & 19 & Zygoma & No complication \\
\hline 56 & 16 & Zygoma & No complication \\
\hline 57 & 45 & Le Fort 2 & No complication \\
\hline 58 & 15 & Le Fort 2 & Presence of \\
\hline 59 & 14 & Zygoma & complication \\
\hline 60 & 27 & Zygoma & No complication \\
\hline 61 & 29 & Unilat Le Fort $2+$ zygoma & No complication \\
\hline 62 & 17 & Le Fort 2 & No complication \\
\hline 63 & 22 & Zygoma & No complication \\
\hline 64 & 23 & Le Fort 2 + zygoma & No complication \\
\hline 65 & 25 & Le Fort 2 + zygoma & No complication \\
\hline 66 & 30 & Le Fort 2 + zygoma & No complication \\
\hline 67 & 21 & Le Fort 2 + zygoma & No complication \\
\hline 68 & 18 & Le Fort 2 + zygoma & No complication \\
\hline 69 & 16 & Le Fort 2 + zygoma & No complication \\
\hline 70 & 20 & Le Fort 2 + zygoma & No complication \\
\hline 71 & 16 & Le Fort 2 + zygoma & No complication \\
\hline 72 & 18 & Le Fort 2 + zygoma & No complication \\
\hline 73 & 14 & Le Fort 2 + zygoma & No complication \\
\hline 74 & 17 & Le Fort 2 & No complication \\
\hline 75 & 18 & Le Fort 2 & No complication \\
\hline 76 & 25 & Le Fort 2 & No complication \\
\hline 77 & 19 & Unilat Le Fort 2 + zygoma & No complication \\
\hline 78 & 13 & Zygoma & No complication \\
\hline 79 & 16 & Zygoma & No complication \\
\hline 80 & 28 & Zygoma & No complication \\
\hline 81 & 24 & Zygoma & No complication \\
\hline 82 & 30 & Zygoma & No complication \\
\hline 83 & 20 & Zygoma & No complication \\
\hline 84 & 18 & Orbital floor & No complication \\
\hline 85 & 15 & Orbital floor & No complication \\
\hline 86 & 23 & Orbital floor & No complication \\
\hline 87 & 24 & Isolated orbital rim & No complication \\
\hline
\end{tabular}

palpebral transcutaneous approach. The limitation of this study, data were obtained from a single center, and there were only two surgeons who performed all the operations. The two surgeons who performed these operations are well versed having performed the surgery many times. Therefore, observed complications in this series are low. This result may not be reproducible in other centers with many surgeons with varying expertise.

\section{Conclusion}

The preseptal transconjuctival approach is a versatile approach that can be used in all midface and orbital fractures situation because of relatively low complication outcomes. The transconjunctival approach did not produce unsightly scar which is almost inevitable when the transcutaneous approach is applied.

\section{Clinical significance}

Facial esthetic concerns are an important part of the management of facial fractures. To achieve a perfect anatomical reduction in treating midfacial fractures, the surgeon must evaluate the best approach with the lowest complications and highest aesthetic outcome; hence the preseptal transconjunctival approach is coined. We believe even though the learning curve for a transconjunctival approach takes longer than transcutaneous approach, the result is most rewarding when the unsightly surgical scar is avoided.

\section{ReFERENCES}

1. Appling WD, Patrinely JR, Salzer TA. Transconjunctival Approach vsSubciliary Skin-Muscle Flap Approach for Orbital Fracture Repair. Arch Otolaryngol Head Neck Surg 1993;119(9):1000-1007.

2. Bourguet, JV. Les herniesgraisseuses de l'orbite, Notre traitement chirurgical. Bull Acad Med (Paris) 1924:92:1270.

3. Tessier, P. The conjunctival approach to the orbital floor and maxilla in congenital malformation and trauma. J Maxillofac Surg 1973;1(1): 3-8.

4. Mullins JB, Holds JB, Branham GH, et al. Complicatios of the transconjunctival approach, a review of 400 cases. Arch Otolaryngol Head Neck Surg 1997:123(4):385-388.

5. Waite PD, Carr DD. The transconjunctival approach for treating orbital trauma. J Oral Maxillofac Surg 1991;49(5):499-503.

6. Holtmann B, Wray RC, Little AG. A randomised comparison of four incisions for orbital fractures. Plast Reconstr Surg 1981;67(6): 731-737.

7. Nordin R, Rahman NA, Rashdi MF, et al. Oral and Maxillofacial trauma caused by road traffic accident in two university hospitals in Malaysia: A cross sectional study. J Oral Maxillofac Surg Med Pathol 2015;27(2):166-171.

8. Ramli R, Rahman RA, Hussaini HM, et al. A retroseptive study of oral and maxillofacial injuries in Seremban Hospital. Dent Traumatol 2011;27(2):122-126.

9. Ramli R, Oxley J, Hillard P, et al. The effect of motorcycle helmet type, components and fixation status on facial injury in Klang Valley, Malaysia: a case control study. BMC Emergenc Med 2014;14:17

10. Baumann A, Ewers R. Use of the preseptaltransconjunctival approach in orbit reconstruction surgery. J Oral Maxillofac Surg 2001;59(3):287291.

11. Novelli G, Ferrari L, Sozzi D, et al. Transconjunctival approach in orbital traumatology: A review of 56 cases. J Craniomaxillofac Surg 2011;39(4):266-270.

12. Magnus WW, CastnerJr DV, Schonder AA, et al. A conjunctival approach to repair of fracture of medial wall of the orbit: report of a case. J Oral Surg 1971;29(9):664-667.

13. Manganello-Souza LC, de Freitas RR. Transconjunctival approach to zygomatic and orbital floor fractures. Int J Oral Maxillofac Surg 1997;26(1):31-34.

14. Patel PC, Sobota BT, Patel NM, Greene JS, Millman B. Comparison of transconjunctival versus subciliary approaches for orbital fractures: A review of 60 cases. J Craniomaxillofac Trauma 1998;4(1):17-21.

15. Wray RC, Holtmann B, Ribaudo JM, et al. A comparison of conjunctival and subciliary incisions for orbital fractures. Br J Plast Surg 1977;30(2):142-145. 